\title{
Retraction Note to: Ethnic Characterization in Amalgamated People for Airport Security Using a Repository of Images and Pigeon-Inspired Optimization (PIO) Algorithm for the Improvement of Their Results
}

\begin{abstract}
Alberto Ochoa-Zezzatti, José Mejía, Roberto Contreras-Masse, Erwin Martínez and Andrés Hernández
\end{abstract}

\section{Retraction Note to:}

Chapter "Ethnic Characterization in Amalgamated People for Airport Security Using a Repository of Images and Pigeon-Inspired Optimization (PIO) Algorithm for the Improvement of Their Results" in: D. Oliva and S. Hinojosa (eds.), Applications of Hybrid Metaheuristic Algorithms for Image Processing, Studies in Computational Intelligence 890, https://doi.org/10.1007/978-3-030-40977-7_5

The editors have retracted this chapter because it significantly overlaps with a previously published article by Duan and Qiao [1] and a previously published conference paper by Cruz-Álvarez et al. [2]. Additionally, a small section of the chapter appears to be generated by computer software, potentially Mathgen. The editors therefore no longer have confidence in the validity of this chapter.

The authors have not responded to correspondence regarding this retraction notice.

[1] Duan, H. and Qiao, P. (2014), "Pigeon-inspired optimization: a new swarm intelligence optimizer for air robot path planning", International Journal of Intelligent Computing and Cybernetics, Vol. 7 No. 1, pp. 24-37. https://doi.org/10.1108/IJICC02-2014-0005

[2] Cruz-Álvarez V.R., Montes-Gonzalez F., Ochoa A., Palacios-Leyva R.E. (2012) Distribution and Selection of Colors on a Diorama to Represent Social Issues

The retracted version of this chapter can be found at https://doi.org/10.1007/978-3-030-40977-7_5 
Using Cultural Algorithms and Graph Coloring. In: Omatu S., De Paz Santana J., González S., Molina J., Bernardos A., Rodríguez J. (eds) Distributed Computing and Artificial Intelligence. Advances in Intelligent and Soft Computing, vol 151. Springer, Berlin, Heidelberg. https://doi.org/10.1007/978-3-642-28765-7_8

The retracted chapter and book have been updated with the changes. 